Original Research Paper

\title{
Fast Food Consumption and Body Mass Index
}

\author{
Vasanthakumar N. Bhat \\ Department of Management, Lubin School of Business, Pace University, New York, USA
}

Article history

Received: $28-04-2015$

Revised: $12-07-2016$

Accepted: 13-07-2016

Email:vbhat@pace.edu

\begin{abstract}
Fast food consumption has been considered a major cause of obesity all over the world. The purpose of this paper is to examine the association between the average frequencies of eating a meal from a fastfood restaurant per week and Body Mass Index (BMI). Our analysis based on a nationwide survey of Americans indicates that a meal from a fast food restaurant per week, on an average, is associated with an increase of BMI of 0.16 or 0.17 after adjusting for race, gender, education, marital status, age and income. However, our analysis does not find a similar effect for meals eaten from any other restaurant. Our analysis also finds that the higher is a person's BMI, the more importance a person assigns to the cause of his obesity being the kinds of foods marketed in restaurants and grocery stores.
\end{abstract}

Keywords: Body Mass Index, Obesity, Fast Food Restaurants

\section{Introduction}

Fast food consumption is a significant public policy issue. Fast food has been considered a major source of obesity and associated health problems and has been targeted by policy makers as a way to reduce rising obesity. According to the US Center for Disease Control, obesity rates in the U.S. have risen dramatically during the last twenty years (Troiano and Flegal, 1998; Flegal et al., 2001; Ogden et al., 2012b). Over one in three adults and one in six children and teens aged 2-19 years are obese (Ogden et al., 2012a). Obesity-related conditions include heart disease, stroke, type-2 diabetics and some types of cancers. They are serious and expensive and costs $\$ 147$ billion in 2008. In comparison to a person with normal weight, an obese person requires $\$ 1497$ more in medical costs per year (Finkelstein et al., 2009).

The fast food industry spent $\$ 4.6$ billion on advertisements in 2012 representing 12 times as much as combined advertisement spending on all milk, bottled water, fruit and veggie. In addition, according to the report published by the Yale Rudd Center for Food Policy and Obesity, one in three children (ages 2-11) and two in five teens (ages 12-19) consumed fast food on the previous day of the survey. This not only increased daily calories, but sugar, saturated fat and sodium intakes as well. Moreover, $36 \%$ of adults consumed fast food on the previous day of the survey (Harris, 2013). Therefore, a number of policy options have been considered and implemented to reduce fast food consumption. For example, several countries have or are considering imposing fat taxes. Los Angeles in California, US banned the establishment of new fast food restaurants for a year in 2008 (Sturm and Cohen, 2009). In addition, the laws have been enacted in several localities in the US requiring compulsory labeling of calories (Elbel, 2011).

Consumption of fast food has increased greatly since 1970 's. At the same time, the prevalence of obesity has also increased in the US. Many scholars attribute the rise in obesity to the increased consumption of fast food. They point to the fast foods' poor nutritional quality (O'Donnell et al., 2008; Lin and Guthrie, 2012). Fast foods are also higher in solid fats than foods consumed at home or school (Poti et al., 2013). A moot point is whether consumption of fast foods increases obesity. The purpose of this paper is to examine the link between fast food consumption and body mass index and quantify the impact of fast food consumption on BMI. We also examine the association between meals eaten at other restaurants and BMI. We also explore the opinions of people about kinds of foods marketed and obesity. A person with a BMI of 30 or over is considered obese. The BMI is estimated using the formula: Mass*703/(height*height) where mass is measured in pounds and height in inches.

This paper is organized into five sections. In the next section, we provide a brief review of literature followed by the methodology. We present analysis of results in the subsequent section. We close this paper with conclusions in the last section.

\section{Literature Review}

The literature on obesity and fast food consumption is vast. Therefore, we limit ourselves to studies that 
examine the association between fast food consumption and BMI. Parallel to the rise in food consumption and increased household expenditures on food bought especially from fast food outlets, there is also an increase in obesity levels in the US (Stewart et al., 2004; Guthrie et al., 2002; Nielsen et al., 2002). Using the National Health and Nutrition Examination Surveys (NHANES), Kant and Graubard (2006) find increased consumption in quantity and energy density of foods between 1976 and 1980 and 1999 and 2002. Putnam et al. (2002) observed that per capita calorie intake increased by more than $40 \%$ and the energy intake came from added sugar and fats, which contribute to obesity. According to Binkley et al. (2000), there is a significant association between fast food consumption and increased BMI after accounting for demographic, lifestyle and regional factors. They used secondary data from the 1994-1996 Continuing Survey of Food Intakes by Individuals. French et al. (2000) found a positive association between the use of fast food restaurants and energy and fat intake and body weight index. This study was based on women in the age group 20 to 45 who were enrolled in the Pound of Prevention study. Bowman and Vinyard (2004) using data from USDA's 1994 to 1996 Continuing Survey of Food Intakes by Individuals (CSFII 1994-1996) examined diet quality and overweight status. Their study found that high energy and energy density in the food consumed by men and women who consumed fast food. They also found that people who consumed fast food on one of two survey days had higher mean BMI than who did not consume fast food on any of two survey days. Bezerra et al. (2012) based on 20 cross-sectional studies and 8 prospective cohort studies found a strong association between out-of-home eating and body weight. According to them, 7 out of 8 prospective cohort studies and about half of cross sectional studies indicate positive association between out-of-home eating and body weight. Based on 54 research studies, Larson et al. (2009) find that neighborhood residents with easy accessibility to supermarkets and limited accessibility to convenient stores tend to be less obese because of healthier diets. Based on the analysis of responders of 2005 Michigan Behavioral Risk Factor Survey Anderson et al. (2011) find a strong association between fast food consumption and obesity. According Kruger et al. (2008), based on the 2004 Styles survey, find that reducing consumption of fast food can help people to maintain lower weights. Mozaffarian et al. (2011) find that consumption of French fries and soft drinks is associated with weight gain. According to Pereira et al. (2005), fast food consumption is positively associated with increased weight and insulin resistance. This indicates likely link between fast food consumption and obesity and type-2 diabetics. Duffey et al. (2007) find differential effect on weight because of eating at restaurants and fast food outlets. Duffey et al. (2009) also find likely adverse metabolic health outcomes from fast food consumption.

The United States Department of Agriculture (USDA, 2013) has done an excellent summary of the literature on the association between fast food consumption and BMI 2013. It cites six major studies, which were all done in the US. One study is based on meta-analysis of previous 16 studies (Rosenheck, 2008). Based on five prospective cohort studies (Duffey et al., 2007; French et al., 2000; Li et al., 2009; Niemeier et al., 2006; Pereira et al., 2005), the USDA concludes that there is a strong association between fast food consumption and BMI. These studies had sample sizes ranging from 891 to 919 .

This paper has two goals. One is to examine the association between the consumption of fast food and BMI and quantify the influence. According to Duffey et al. (2007) we know little about the independent effect of fast food intake and consumption of food from restaurants on BMI. Therefore, our second objective is to examine the influence of fast food intake and consumption of food from any restaurant on BMI. We also examine people's opinions to explore the reasons for obesity by eating meals at fast food restaurants.

\section{Methodology}

According to Spiegelman and Flier (2001), caloric intake combined with genetic and metabolic factors governs body weight and composition. Therefore, the food choices made by people have significant impact on their body weight. Based on data analysis done by (Kant and Graubard, 2006; Putnam et al., 2002), the per capita calorie consumption increased by more than 300 kilocalories in the US between 1985 and 2002 . Prentice and Jebb (2003) reason that the association between fast foods and higher body weights is because of larger portion sizes and high energy density of fast foods.

With a view to examine whether there are differential effects from eating at fast food restaurants like McDonald's or Burger King and at any other restaurants, we use a survey of nationwide random sample of the U.S. population conducted by (STR, 2006). This survey, consisting of more than 110 variables, is based on a randomly selected sample of more than 1700 people. The obesity is measured using BMI. The fast food consumption is measured in terms of frequency of meals consumed per week from fast food restaurants like McDonald's or Burger King. The observations are statistically weighed to reflect the US demographics. We present both univariate analysis and multivariate analysis. We first examine BMI, frequency of consumption of fast food per week and obesity by 
various demographic variables. We also do correlation analysis to explore the association between the obesity and the frequency of consumption of fast food. We then carry out multivariate analysis using generalized linear model with the dependent variable to be normally distributed and link function to be the identity. We use BMI as a dependent variable and frequencies of fast food consumption per week and food consumption from any restaurants per week as independent variables. We introduce demographic and other variables as control variables. We use SPSS 20 version to do the analysis.

\section{Analysis of Results}

\section{Univariate Analysis}

We begin our analysis with exploratory data analysis of frequency of meals consumed per week from fast food restaurant, frequency of meals consumed per week from any restaurants and BMI. We examine the associations of average number of meals eaten at a fast food restaurant per week, BMI and average number of meals eaten at any restaurant per week with various demographic variables. These results are presented in Table 1 . We find that the Pearson correlation between the average number of meals eaten at a fast food restaurant and BMI are positive and is statistically significant at the 0.05 level.

The negative Pearson correlation between the average number of meals per week consumed at a fast food restaurant and age indicates that as a person gets older, a person's consumption frequency of meals from fast food restaurant goes down. Similar association is also found between the mean number of meals consumed per week from fast food restaurant and education indicating that higher educated people consume fewer meals from fast food restaurants. Income is also found to have similar effect. In addition, the association between mean number of meals consumed from fast food restaurants and any restaurants is also found to be positive.

We explore relationship between BMI and age, education, income and number of meals consumed per week from any restaurant. BMI is found to be positively associated with age. However, BMI is negatively associated with income and education. A surprising result is that the mean number of meals consumed at any restaurant does not have any statistically significant association with BMI.

The mean number of meals consumed per week from any restaurant is found to be positively associated with education and income. This indicates that higher educated people and higher income people consume food from any restaurant at a higher frequency compared to less educated and lower income people.

We explore mean BMI, frequency of meals per week from fast food restaurants and whether obese (BMI equal to or greater than 30 ) by various personal characteristics. Ours results are presented in Table 2.
An analysis based on gender indicates that men have higher mean BMI (27.09) than women (25.79). One in five men are likely to be obese compared to only $16 \%$ among women. Men have higher frequency of meals per week at fast food restaurants as compared to women.

A comparison based on race indicates that minorities are likely to have higher frequency of meals per week from fast food restaurants than whites. Minorities have higher mean BMI than whites and higher proportion of them are also likely to be obese.

Based on marital status, a single/divorced/separated person has a higher mean number of meals per week consumed from fast food restaurants than a married/living with someone. However, the higher proportions of married/living with someone are obese and have higher mean BMI.

There is no obvious association between education and obesity. People with post-graduate training or professional schooling after college and college graduates have the lowest proportion of people obese. Persons with technical trade or vocational education after high school, high school incomplete ( 9 to 11 grades) and grades 1 to 8 have lowest proportion of obese people. However, persons with some college and high school graduates have the proportion of obese people in between the proportions of the above-mentioned two categories. High school incomplete (9-11 grades) and high school graduates (Grade 12 or GED certificate) have highest mean number of meals per week from fast food restaurants.

People with income of less than $\$ 100,000$ consume meals from fast food restaurants at higher frequencies than people with income over $\$ 100,000$ consume. The frequency of consuming meals from fast food restaurants peaks for the people with income between $\$ 20,000$ and $\$ 40,000$. BMI decreases with income. The proportions of obese people also decrease with income.

People in the age group between 50 and 64 have the highest proportion of obese people among any age category and people in the age group between 18 and 29 have the lowest. However, people in the age group 18 to 29 have the highest mean number of meals consumed per week from fast food restaurants.

\section{Multivariate Analysis}

We perform generalized linear model analysis with BMI as a dependent variable and various demographic variables as independent variables. The generalized model assumes the dependent variable to be normally distributed and link function to be the identity. Table 3 presents three specifications. In the first specification, gender, race, marital status, education, income, age group and mean number of meals consumed from a fast food restaurant are independent variables. All education-related dummy variables and the dummy variable representing income from $\$ 10,000$ to under $\$ 20,000$ are not statistically significant at the 0.05 
level. All other results are statistically significant at the 0.05 level. Women have 1.36 less BMI than men. Whites have 0.53 less BMI than minorities. Married/living with someone have 0.39 higher BMI than separated/single/divorced. All income groups higher than $\$ 10,000$ have lower BMI than people in the income group less than $\$ 10,000$. All age groups have higher BMI than people in the age group 1829. Each meal consumed at a fast food restaurant every week increases BMI on an average by 0.14 . However, this result is statistically significant only at 0.052 level.

Table 1. The Pearson correlations between the number of meals per week from fast food restaurants, BMI, meals from any restaurant and demographic variables

\begin{tabular}{|c|c|c|c|c|}
\hline & & $\begin{array}{l}\text { Average meals } \\
\text { per week from } \\
\text { any restaurant }\end{array}$ & BMI & $\begin{array}{l}\text { Average meals } \\
\text { per week from fast } \\
\text { food restaurant }\end{array}$ \\
\hline \multirow{3}{*}{$\begin{array}{l}\text { Average number of meals per } \\
\text { week from fast food restaurant }\end{array}$} & Correlation & 1 & $0.063^{* *}$ & $0.176^{* *}$ \\
\hline & Sig. (2-tailed) & & 0.000 & 0.000 \\
\hline & $\mathrm{N}$ & 4898 & 4484 & 4866 \\
\hline \multirow[t]{3}{*}{ BMI } & Correlation & $0.063^{* *}$ & 1 & 0.000 \\
\hline & Sig. (2-tailed) & 0.000 & & 0.991 \\
\hline & $\mathrm{N}$ & 4484 & 4500 & 4480 \\
\hline \multirow[t]{3}{*}{ AGE } & Correlation & $-0.147^{* *}$ & $0.060^{* *}$ & $-0.125^{* *}$ \\
\hline & Sig. (2-tailed) & 0.000 & 0.000 & 0.000 \\
\hline & $\mathrm{N}$ & 4898 & 4500 & 4881 \\
\hline \multirow[t]{3}{*}{ Highest grade completed in School } & Correlation & $-0.071^{* *}$ & $-0.106^{* *}$ & $0.143^{* *}$ \\
\hline & Sig. (2-tailed) & 0.000 & 0.000 & 0.000 \\
\hline & $\mathrm{N}$ & 4867 & 4485 & 4855 \\
\hline \multirow[t]{3}{*}{ Income from all sources } & Correlation & $-0.042^{* *}$ & $-0.098^{* *}$ & $0.188^{* *}$ \\
\hline & Sig. (2-tailed) & 0.007 & 0.000 & 0.000 \\
\hline & $\mathrm{N}$ & 4124 & 3887 & 4117 \\
\hline \multirow[t]{3}{*}{ Meals per week from any restaurant } & Correlation & $0.176^{* *}$ & 0.000 & 1 \\
\hline & Sig. (2-tailed) & 0.000 & 0.991 & \\
\hline & $\mathrm{N}$ & 4866 & 4480 & 4881 \\
\hline
\end{tabular}

**Statistically significant at the 0.01 level

Table 2. Body Mass Index (BMI), average number of meals per week from fast food restaurant and whether obese by various personal characteristic

\begin{tabular}{|c|c|c|c|c|c|c|}
\hline & & $\mathrm{N}$ & Percent & BMI & $\begin{array}{l}\text { Meals per week } \\
\text { from fast food } \\
\text { restaurants }\end{array}$ & $\begin{array}{l}\text { lobese } \\
\text { not } \\
\text { obese }\end{array}$ \\
\hline \multirow[t]{2}{*}{ Gender } & Female & 1907 & 50.7 & 25.79 & 0.3658 & 0.16 \\
\hline & Male & 1854 & 49.3 & 27.09 & 0.4649 & 0.20 \\
\hline \multirow[t]{2}{*}{ Race } & White & 3034 & 80.7 & 26.35 & 0.3790 & 0.18 \\
\hline & Minority & 727 & 19.3 & 26.83 & 0.5424 & 0.19 \\
\hline \multirow[t]{2}{*}{ Marital status } & married/living with someone & 2295 & 61.0 & 26.49 & 0.3820 & 0.18 \\
\hline & separated/single/divorced & 1466 & 39.0 & 26.39 & 0.4674 & 0.17 \\
\hline \multirow[t]{7}{*}{ Education } & Post-graduate training or professional schooling after college & 422 & 11.2 & 25.08 & 0.2015 & 0.13 \\
\hline & College graduate (B.S., B.., or other 4-year degree) & 606 & 16.1 & 25.81 & 0.3134 & 0.14 \\
\hline & Some college, no 4-year degree (including associate degree) & 893 & 23.7 & 26.39 & 0.3982 & 0.20 \\
\hline & Technical, trade, or vocational school AFTER high school & 150 & 4.0 & 26.94 & 0.2766 & 0.16 \\
\hline & High school graduate (Grade 12 or GED certificate) & 1208 & 32.1 & 26.98 & 0.5615 & 0.20 \\
\hline & High school incomplete (Grades 9-11) & 369 & 9.8 & 26.61 & 0.5307 & 0.17 \\
\hline & None, or grade $1-8$ & 113 & 3.0 & 27.78 & 0.1403 & 0.18 \\
\hline \multirow[t]{9}{*}{ Income } & $\$ 150,000$ or more & 225 & 6.0 & 25.77 & 0.1988 & 0.15 \\
\hline & 100 to under $\$ 150,000$ & 316 & 8.4 & 25.77 & 0.2507 & 0.17 \\
\hline & 75 to under $\$ 100,000$ & 494 & 13.1 & 26.53 & 0.4654 & 0.18 \\
\hline & 50 to under $\$ 75,000$ & 659 & 17.5 & 25.88 & 0.4304 & 0.13 \\
\hline & 40 to under $\$ 50,000$ & 438 & 11.6 & 26.26 & 0.4503 & 0.15 \\
\hline & 30 to under $\$ 40,000$ & 508 & 13.5 & 26.03 & 0.6085 & 0.17 \\
\hline & 20 to under $\$ 30,000$ & 462 & 12.3 & 26.82 & 0.5295 & 0.25 \\
\hline & 10 to under $\$ 20,000$ & 419 & 11.1 & 27.65 & 0.4009 & 0.26 \\
\hline & Less than $\$ 10,000$ & 240 & 6.4 & 28.03 & 0.3876 & 0.26 \\
\hline \multirow[t]{4}{*}{ Age group } & $65+$ & 533 & 14.2 & 26.10 & 0.1785 & 0.18 \\
\hline & $50-64$ & 873 & 23.2 & 27.72 & 0.2621 & 0.24 \\
\hline & $30-49$ & 1591 & 42.3 & 26.52 & 0.4394 & 0.18 \\
\hline & $18-29$ & 764 & 20.3 & 25.16 & 0.7439 & 0.13 \\
\hline Total & & 3761 & 100.0 & 26.46 & 0.4170 & 0.18 \\
\hline
\end{tabular}




\begin{tabular}{|c|c|c|c|c|c|c|c|}
\hline \multicolumn{2}{|l|}{ Variables } & $\begin{array}{l}\text { Para- } \\
\text { meters }\end{array}$ & $\begin{array}{l}\text { Wald Chi- } \\
\text { Square }\end{array}$ & $\begin{array}{l}\text { Para- } \\
\text { meters }\end{array}$ & $\begin{array}{l}\text { Wald Chi- } \\
\text { Square }\end{array}$ & $\begin{array}{l}\text { Para- } \\
\text { meters }\end{array}$ & $\begin{array}{l}\text { Wald Chi- } \\
\text { Square }\end{array}$ \\
\hline \multicolumn{2}{|l|}{ Intercept } & 26.98 & 1715.31 & 27.42 & 3792.900 & 27.40 & 3735.60 \\
\hline \multirow[t]{2}{*}{ Gender } & Female & -1.36 & 55.47 & -1.40 & 59.090 & -1.38 & 57.10 \\
\hline & Male & 0.00 & 0.00 & 0.00 & 0.000 & 0.00 & 0.00 \\
\hline \multirow[t]{2}{*}{ Race } & White & -0.53 & 5.28 & -0.50 & 4.680 & -0.49 & 4.47 \\
\hline & Minority & 0.00 & 0.00 & 0.00 & 0.000 & 0.00 & 0.00 \\
\hline \multirow[t]{2}{*}{ Marital status } & married/living with someone & 0.39 & 3.92 & 0.38 & $3.71 *$ & 0.38 & $3.71 *$ \\
\hline & separated/single/divorced & 0.00 & 0.00 & 0.00 & 0.000 & 0.00 & 0.00 \\
\hline \multirow[t]{7}{*}{ Education } & Post-graduate training or professional schooling after college & -0.77 & $1.54 *$ & & & & \\
\hline & College graduate (B.S., B.., or other 4-year degree) & -0.14 & $0.05 *$ & & & & \\
\hline & Some college, no 4-year degree (including associate degree) & 0.50 & $0.75 *$ & & & & \\
\hline & Technical, trade, or vocational school AFTER high school & 1.09 & $2.40 *$ & & & & \\
\hline & High school graduate (Grade 12 or GED certificate) & 0.73 & $1.73 *$ & & & & \\
\hline & High school incomplete (Grades 9-11) & 0.14 & $0.06^{*}$ & & & & \\
\hline & None, or grade $1-8$ & 0.00 & 0.00 & & & & \\
\hline \multirow[t]{9}{*}{ Income } & $\$ 150,000$ or more & -2.35 & 18.54 & -2.84 & 29.79 & -2.94 & 31.12 \\
\hline & 100 to under $\$ 150,000$ & -2.86 & 30.59 & -3.29 & 45.74 & -3.32 & 45.61 \\
\hline & 75 to under $\$ 100,000$ & -2.08 & 19.49 & -2.31 & 26.96 & -2.35 & 27.29 \\
\hline & 50 to under $\$ 75,000$ & -2.73 & 37.58 & -2.86 & 45.81 & -2.89 & 46.15 \\
\hline & 40 to under $\$ 50,000$ & -2.11 & 20.72 & -2.14 & 23.16 & -2.17 & 23.53 \\
\hline & 30 to under $\$ 40,000$ & -2.30 & 26.96 & -2.31 & 28.64 & -2.33 & 28.82 \\
\hline & 20 to under $\$ 30,000$ & -1.49 & 11.15 & -1.40 & 10.24 & -1.43 & 10.52 \\
\hline & 10 to under $\$ 20,000$ & -0.43 & $0.92 *$ & -0.41 & $0.84 *$ & -0.47 & $1.11 *$ \\
\hline & Less than $\$ 10,000$ & 0.00 & 0.00 & 0.00 & 0.00 & 0.00 & 0.00 \\
\hline \multirow[t]{4}{*}{ Age group } & $65+$ & 1.52 & 22.23 & 1.44 & 20.07 & 1.46 & 20.45 \\
\hline & $50-64$ & 3.25 & 133.90 & 3.24 & 134.25 & 3.26 & 135.86 \\
\hline & $30-49$ & 2.06 & 68.02 & 2.00 & 64.14 & 2.01 & 64.83 \\
\hline & $18-29$ & 0.00 & 0.00 & 0.00 & 0.00 & 0.00 & 0.00 \\
\hline \multicolumn{2}{|c|}{ Number of meals eaten per week from fast-food restaurant like } & 0.14 & $3.77 *$ & 0.17 & 5.31 & 0.16 & 4.13 \\
\hline \multicolumn{8}{|c|}{ McDonald's or Burger King? } \\
\hline \multicolumn{2}{|c|}{ Number of meals eaten per week from restaurants } & & & & & 0.02 & $0.07 *$ \\
\hline \multicolumn{2}{|c|}{ Scale (maximum likelihood estimate) } & 29.82 & & 30.022 & & 30.06 & \\
\hline \multicolumn{2}{|c|}{ Number of observations $($ sample size $=1716$ ) } & 3761.00 & & 3761.000 & & 761.00 & \\
\hline \multicolumn{2}{|c|}{ Log likelihood } & 23488.00 & & 23533.000 & & 459.00 & \\
\hline \multicolumn{2}{|c|}{ Akaike's Information Criterion (AIC) } & -11721.00 & & -11750.000 & & 712.00 & \\
\hline
\end{tabular}

All variables without * statistically significant at the 0.05 level

Since no dummy variable representing education is statistically significant, we remove them in the second specification. The results are similar except for marital status that is no longer statistically significant at the 0.05 level. Each meal consumed from a fast food restaurant every week increases BMI by 0.17 and this result is statistically significant at the 0.05 level.

In the third specification, independent variables are identical to specification two. However, we add mean number of meals eaten per week from any restaurant. Again, the results are similar to those in specification two. We also find that the influence of mean number of meals consumed per week from any restaurant on BMI is positive, but the result is not statistically significant at the 0.05 level.

To sum up, our analysis indicates that a meal consumed from a fast food restaurant per week increases BMI by 0.16 to 0.17 after accounting for gender, race, marital status, income and age group. However, the number of meals consumed at any restaurant per week does not have any statistically significant effect on BMI. This is an important result as Duffey et al. (2007) have found similar differing results. In addition, our analysis indicates a negative association between income and BMI. Our analysis also finds that people in the age group 18-29 have the lowest BMI even though they have the highest mean number of meals from the fast food restaurants.

To probe further, we examine the association of average number of meals consumed per week from fast food restaurant and BMI with the response to the question whether the kinds of foods marketed at restaurants and grocery stores as a reason for they being overweight. Each response is coded on a scale of 1 to 4 with 1 being very important, 2 somewhat important, 3 not too important and 4 not at all important reason for being overweight. We perform the Pearson and the Spearman correlations. Both correlations are found to be negative and statistically significant at the 0.01 . This indicates that more obese a person is, more he feels that the kinds of foods marketed in restaurants and grocery stores being important cause of his or her obesity.

\section{Conclusion}

Fast food consumption has been considered a major cause of obesity in the US. The purpose of this paper is 
to examine the association between the average frequencies of eating a meal from a fast-food restaurant per week and Body Mass Index (BMI). Our analysis, based on a nationwide survey of Americans, indicates that every meal from a fast food restaurant per week is associated with an average increase of the BMI of 0.16 or 0.17 , after adjusting for race, gender, education, marital status, age and income.

We do similar analysis for meals eaten from any other restaurants and we do not find any association between meals eaten and BMI. Based on this lack of association, we may argue that meals eaten at restaurants other than fast foods may be nutritionally better. In addition, the positive association between education and income with meals eaten at other restaurants may bolster this argument. However, no such definite conclusion can be drawn because of lack of uniformity in foods served among any restaurant that are not fast food.

When people were asked to rank on a scale from very important to not at all important whether the kinds of foods marketed in restaurants and grocery stores being cause for their obesity, the ranking increased from not at all important to very important as obesity measured in BMI increased. In other words, the higher is a person's BMI, the more importance a person assigns to the reason for their obesity being the kinds of foods marketed in restaurants and grocery stores.

There are a vast number of research papers analyzing the association between obesity and fast food consumption. Some of these papers use the accessibility of fast food as a proxy for fast food consumption. Others examined the frequency of consumption of fast food and BMI. This paper falls in the second category. This paper also tries to examine whether the frequencies of consumption of food from any restaurant have any impact on BMI. More research is needed to identify factors that influence a person to eat fast food in the first place.

Rising obesity rates are likely to increase the prevalence of chronic diseases. Therefore, it is important to discourage consumption of fast foods. Increasing prices of fast foods and reducing prices of healthy foods can promote consumption of healthy foods. Encouraging people to follow healthy lifestyles that include daily physical exercise should also be encouraged.

\section{Acknowledgement}

The author has no acknowledgement to report.

\section{Funding Information}

The author has no funding to report.

\section{Ethics}

This article is work of the author with no contribution from any other person. The author declares no conflict of interest with any institution for the publication of this paper.

\section{References}

Anderson, B., A.P. Rafferty, S. Lyon-Callo, C. Fussman and G. Imes, 2011. Fast-food consumption and obesity among Michigan adults. Prev. Chronic Dis., 8: A71-A71.

Bezerra, I.N., C. Curioni and R. Sichieri, 2012. Association between eating out of home and body weight. Nutr. Rev., 70: 65-79. DOI: $10.1111 /$ j.1753-4887.2011.00459.x

Binkley, J.K., J. Eales and M. Jekanowski, 2000. The relation between dietary change and rising US obesity. Int. J. Obesity, 24: 1032-1039.

DOI: $10.1038 /$ sj.ijo.0801356

Bowman, S.A. and B.T. Vinyard, 2004. Fast food consumption of U.S. adults: Impact on energy and nutrient intakes and overweight status. J. Am. College Nutr., 23: 163-168.

DOI: $10.1080 / 07315724.2004 .10719357$

Duffey, K.J., P. Gordon-Larsen, D.R.J. Jacobs, O.D. Williams and B.M. Popkin, 2007. Differential associations of fast food and restaurant food consumption with $3-y$ change in body mass index: The Coronary artery risk development in young adults study. Am. J. Clin. Nutr., 85: 201-208. PMID: 17209197

Duffey, K.J., P. Gordon-Larsen, L.M. Steffen, D.R.J. Jacobs and B.M. Popkin, 2009. Regular consumption from fast food establishments relative to other restaurants is differentially associated with metabolic outcomes in young adults. J. Nutr., 139: 2113-2118. PMID: 19776183

Elbel, B., 2011. Consumer estimation of recommended and actual calories at fast food restaurants. Obesity, 19: 1971-1978. DOI: 10.1038/oby.2011.214

Finkelstein, E.A., J.G. Trogdon, J.W. Cohen and W. Dietz, 2009. Annual medical spending attributable to obesity: Payer-and service-specific estimates. Health Affairs, 28: w822-w831.

DOI: $10.1377 /$ hlthaff.28.5.w822

Flegal, K.M., C.L. Ogden, R. Wei, R.L. Kuczmarski and C.L. Johnson, 2001. Prevalence of overweight in US children: Comparison of US growth charts from the centers for disease control and prevention with other reference values for body mass index. Am. J. Clin. Nutr., 73: 1086-1093. PMID: 11382664

French, S.A., L. Harnack and R.W. Jeffery, 2000. Fast food restaurant use among women in the pound of prevention study: Dietary, behavioral and demographic correlates. Int. J. Obesity, 24: 1353-1359.

DOI: $10.1038 /$ sj.ijo.0801429 
Guthrie, J.F., B.H. Lin and E. Frazão, 2002. Role of food prepared away from home in the American diet, 1977-78 versus 1994-96: Changes and consequences. J. Nutrit. Educ. Behav., 34: 140-150. DOI: 10.1016/S1499-4046(06)60083-3

Harris, J.L., 2013 Fast food FACTS 2013: Measuring progress in nutrition and marketing to children and teens. Yale Rudd Center for Food Policy and Obesity.

Kant, A.K. and B.I. Graubard, 2006. Secular trends in patterns of self-reported food consumption of adult Americans: NHANES 1971-1975 to NHANES 1999-2002. Am. J. Clin. Nutr., 84: 1215-1223. PMID: 17093177

Kruger, J., H.M. Blanck and C. Gillespie, 2008. Dietary practices, dining out behavior and physical activity correlates of weight loss maintenance. Prev. Chronic Dis., 5: A11-A11. PMID: 18082000

Larson, N.I., M.T. Story and M.C. Nelson, 2009. Neighborhood environments: Disparities in access to healthy foods in the U.S. Am. J. Prev. Med., 36: 74-81. DOI: 10.1016/j.amepre.2008.09.025

Li, F., P. Harmer, B.J. Cardinal, M. Bosworth and D. Johnson-Shelton et al., 2009. Built environment and 1-year change in weight and waist circumference in middle-aged and older adults: Portland neighborhood environment and health study. Am. J. Epidemiol., 169: 401-408. DOI: 10.1093/aje/kwn398

Lin, B.H. and J. Guthrie, 2012. Nutritional Quality of Food Prepared at Home and Away from Home, 1977-2008. 1st Edn., DIANE Publishing Company, Washington, D.C., ISBN-10: 145784253X, pp: 24.

Mozaffarian, D., T. Hao, E.B. Rimm, W.C. Willett and F.B. $\mathrm{Hu}, 2011$. Changes in diet and lifestyle and long-term weight gain in women and men. New Engl. J. Med., 364: 2392-2404. DOI: $10.1056 /$ NEJMoa1014296

Nielsen, S.J., A.M. Siega-Riz and B.M. Popkin, 2002. Trends in food locations and sources among adolescents and young adults. Preventive Med., 35: 107-113. DOI: 10.1006/pmed.2002.1037

Niemeier, H.M., H.A. Raynor, E.E. Lloyd-Richardson, M.L. Rogers and R.R. Wing, 2006. Fast food consumption and breakfast skipping: Predictors of weight gain from adolescence to adulthood in a nationally representative sample. J. Adolesc. Health, 39: 842-849. DOI: 10.1016/j.jadohealth.2006.07.001

O'Donnell, S.I., S.L. Hoerr, J.A. Mendoza and E. Tsuei Goh, 2008. Nutrient quality of fast food kids meals. Am. J. Clin. Nutr., 88: 1388-1395. PMID: 18996876
Ogden, C.L., M.D. Carroll, B.K. Kit and K.M. Flegal, 2012a. Prevalence of obesity in the United States, 2009-2010. NCHS Data Brief, 82: 1-8. PMID: 22617494

Ogden, C.L., M.D. Carroll, B.K. Kit and K.M. Flegal, 2012b. Prevalence of obesity and trends in body mass index among US children and adolescents, 1999-2010. JAMA, 307: 483-490.

DOI: $10.1001 /$ jama.2012.40

Pereira, M.A., A.I. Kartashov, C.B. Ebbeling, L. Van Horn and M.L. Slattery et al., 2005. Fast-food habits, weight gain and insulin resistance (the CARDIA study): 15-year prospective analysis. Lancet, 365: 36-42. DOI: 10.1016/S0140-6736(04)17663-0

STR, 2006. Pew Research Center Survey. Social Trends Reports.

Poti, J., M. Slining and B. Popkin, 2013. Solid fat and added sugar intake among US children: The role of stores, schools and fast food from 1994 to 2010. Am. J. Prev. Med., 45: 551-559. DOI: $10.1016 /$ j.amepre.2013.06.013

Prentice, A.M. and S.A. Jebb, 2003. Fast foods, energy density and obesity: A possible mechanistic link. Obes. Rev. 4: 187-194. DOI: $10.1046 /$ j.1467-789X.2003.00117.x

Putnam, J., J. Allshouse and L.S. Kantor, 2002. US per capita food supply trends: Morecalories, refined carbohydrates and fats. Food Rev., 25: 1-15.

Rosenheck, R., 2008. Fast food consumption and increased caloric intake: A systematic review of a trajectory towards weight gain and obesity risk. Obes. Rev., 9: 535-547. PMID: 18346099

Spiegelman, B.M. and J.S. Flier, 2001. Obesity and the regulation of energy balance. Cell, 104: 531-543. DOI: 10.1016/S0092-8674(01)00240-9

Stewart, H., N. Blisard, S. Bhuyan and R.M. Nayga Jr., 2004. The demand for food away from home: Full service or fast food? United States Department of Agriculture, Agricultural Economic Report Series.

Sturm, R. and D. Cohen, 2009. Zoning for health? the year-old ban on new fast-food restaurants in south LA. Health Aff., 28: w1088-w1097.

DOI: $10.1377 /$ hlthaff.28.6.w1088

Troiano, R.P. and K.M. Flegal, 1998. Overweight children and adolescents: Description, epidemiology and demographics. Pediatrics, 101: 497-504. PMID: 12224656

USDA, 2013. What is the relationship between eating out and body weight in adults? United States Department of Agriculture. 